\title{
Predicting Smoking Behaviors among Junior High School Students in Ghana
}

\author{
Emmanuel Thompson ${ }^{1}$, Seidu Sofo ${ }^{2}$ \\ ${ }^{1}$ Department of Mathematics, Southeast Missouri State University, United States \\ ${ }^{2}$ Department of Health, Human Performance \& Recreation, Southeast Missouri State University, United States
}

\begin{tabular}{l} 
Article Info \\
\hline Article history: \\
Received Aug 25, 2018 \\
Revised Oct 24, 2018 \\
Accepted Nov 13, 2018
\end{tabular}

\section{Keyword:}

Binary logistic regression

C-Index

Forward selection selection

Ghana

\begin{abstract}
Despite the rising rate of smoking in sub-Sahara African countries, measures to control the tobacco epidemic have been limited to developed countries. The purpose of the present study was to recommend predictive models for determining predictors of smoking tendencies among junior high school students in Ghana. The 2009 Global Youth Tobacco Survey (GYTS) served as the data source. The GYTS is a school-based survey designed to enhance the ability of countries to monitor tobacco use among youth and to guide the implementation and evaluation of tobacco control and prevention programs. Logit model and forward selection were used to choose predictive variables for smoking tendencies and behaviors. Receiver Operating Characteristic (ROC) curve, Area under the curve (AUC) and C-Index were validation tools used to assess the predictive power of recommended models. Results showed promising potential for different predictive models: where students smoked, having friends who smoked, having people smoke in their presence, chewing tobacco products, and a student's sex significantly predicted their smoking tendencies.
\end{abstract}

Copyright (c) 2018 Institute of Advanced Engineering and Science. All rights reserved.

\section{Corresponding Author:}

Emmanuel Thompson,

Department of Mathematics,

Southeast Missouri State University,

1 University Plaza, Cape Girardeau, MO 6701, United States.

Email: ethompson@semo.edu

\section{INTRODUCTION}

Tobacco kills a large number of its users when used as prescribed by the manufacturers. Globally, six million people die annually from tobacco use, and estimated to reach eight million by 2030 [1]. Research shows that women and children are the most affected by the drug [2]. Measures to control the epidemic have been limited to developed countries.

Whereas tobacco use appears to be declining in many developed countries, it is increasing in the developing world [3], in part due to the economic growth in some developing countries. Consequently, the tobacco industry is capitalizing on the economic growth in these countries in terms of tobacco advertisements [4]. African countries have lower rates of tobacco taxation, and less stringent tobacco advertising restrictions in comparison to higher income countries [5]. Increasing tobacco taxes by $10 \%$ generally decreases tobacco consumption by about $8 \%$ in low-income and middle-income countries. Many Sub-Saharan countries have failed to allocate the appropriate financial resources to tobacco prevention programs, despite the cost-effectiveness of such programs [6].

Tobacco use is prevalent in Ghana. The common forms of usage include not only cigarette smoking, but also pipe smoking, chewing, sniffing and oral or nasal use [7]. Until recently, there were no studies showing tobacco prevalence for the whole country [8]. The rates of smoking among the general population in Ghana are relatively low, with males smoking more than females [9]. Earlier models of the tobacco epidemic 
failed to explain the long delay between increase in smoking and the increase in smoking-related mortality in developing countries like Ghana [10]. Stage one epidemic is characterized by higher prevalence of smoking among males than females. However, the World Health Organization [11] reported higher rates among the youth, suggesting a rise in the future use. An understanding of smoking patterns among adolescents can shed light on trends in smoking initiation [12]. Growth in the Ghanaian tobacco industry is a concern. The growth has led to the industry targeting the population especially the youth. For example, research shows that tobacco advertisement, permission to smoke on school compounds, and parental smoking were associated with students' intentions to smoke [13].

The Government of Ghana and Civil Society Organizations (CSOs) are putting in place measures to reduce the prevalence of tobacco use in the country. First, CSOs have reached an agreement with the National Development Planning Commission (NDPC) for the inclusion of the Tobacco Control Measures of the Public Health Act in the 40-year development agenda [14]. CSOs who are committed to reducing tobacco addiction and its related diseases and death. School smoking policies and parental smoking behaviors are important in reducing smoking intentions among Ghanaian youth [13]. Furthermore, the literature shows that smokers are likely to have friends who smoke [15].

Research suggests that the rate of smoking among Ghanaian youth could increase in the future. An understanding of the smoking tendencies among the youth in Ghana is warranted. The objectives of the present study included: (1) To recommend an appropriate predictive model to inform policy on tobacco use and control in Ghana and (2)To determine predictors of smoking tendencies among junior high school students (JHS) in Ghana. An understanding of the predictors and appropriate predictive model for smoking tendencies among students would allow public health policymakers and administrators, community leaders, and school administrators to develop effective smoking prevention programs [13], aimed at reducing smoking tendencies among the youth.

\section{RESEARCH METHOD}

The Global Youth Tobacco Survey (GYTS) [16] data on Ghana for 2009 served as the data source. The GYTS is a school-based survey that helps countries monitor tobacco use among youth. The 2009 data are the most current tobacco survey data for Ghana to date. The GYTS also guides in the implementation and evaluation of tobacco control and prevention programs. The $2009(8,295)$ observations and many variables. Of the 8,295 observations, only 5971 (72\%) were analyzed. Approximately 28\% (2324) of the observations were discarded due to missing data.

\subsection{Variables}

The variables used were as follow: The response variable was "Whether a student had ever tried or experimented with cigarette smoking, even one or two puffs?" Thirty-two (32) predictors were used (refer to appendix). Before fitting the logit model, the GYST dataset was divided into two sets: Training and testing. The training set which constituted $70 \%$ of the entire dataset was used to specify the predictive model and the remaining $30 \%$ was used as a testing set to perform out-of-sample validation of the predictive accuracy of the model.

\subsection{Logit model}

Let $Y_{i}$ represent random variables taking values $y_{i} \in(0,1)$ with probability $1-\pi_{i}$ and $\pi_{i}$ respectively. This implies:

$$
f_{\pi_{i}}\left(y_{i}\right)=\pi_{i}^{y_{i}}\left(1-\pi_{i}^{y_{i}}\right)
$$

Suppose the logit of probability of $\pi_{i}$ is given by

$$
\log \left(\frac{\pi_{i}}{1-\pi_{i}}\right)=X_{i}^{T} \beta \Rightarrow \pi_{i}=\frac{e^{X_{i}^{T} \beta}}{1+e^{X_{i}^{T} \beta}} .
$$

The predictive form of (2) can be written as:

$$
\pi\left(\beta \mid X_{i}\right)=\frac{1}{1+e^{-X_{i}^{T} \beta^{\prime}}}
$$

where $X_{i}$ and $\beta$ are vectors of predictors and slopes respectively. 
To estimate (2), the loglikelihood is given by:

$$
\begin{aligned}
l(\beta) & =\log \left[\prod_{i=1}^{n} f_{\pi_{i}}\left(y_{i}\right)\right], \\
& =\sum_{i=1}^{n}\left[y_{i} \log \left(\pi_{i}\right)+\left(1-y_{i}\right) \log \left(1-\pi_{i}\right)\right], \\
& =\sum_{i=1}^{n}\left[y_{i} \log \left(\pi\left(\beta \mid X_{i}\right)\right)+\left(1-y_{i}\right) \log \left(1-\pi\left(\beta \mid X_{i}\right)\right)\right] .
\end{aligned}
$$

Let $\nabla l(\beta)=\frac{\partial l(\beta)}{\partial \beta_{k}}$ and $H(\beta)=\frac{\partial^{2} l(\beta)}{\partial \beta_{k} \partial \beta_{m}}$ represent the gradient of the loglikelihood and the hessian matrix respectively. No closed-form solution, so resort to Newton Raphson's algorithm for approximate solution. Newton Raphson's algorithm [17] is given as follows:

1. Start from some initial values $\beta_{0}$.

2. Set $\beta_{k}=\beta_{k-1} H\left(\beta_{k-1}\right)^{-1} \nabla l\left(\beta_{k-1}\right)$ (a loop).

3. Repeat step 2 until $\beta_{k}$ is close to $\beta_{k-1}$.

Inference is carried out as follows:

$$
\sqrt{n}(\hat{\beta}-\beta) \rightarrow N\left(0, I(\beta)^{-1}\right) \text { as } n \rightarrow \infty,
$$

where $I(\beta)=-H(\beta)$ is fisher information and $I(\beta)^{-1}$ is the variance-covariance matrix.

\subsubsection{Variable selection-forward stepwise selection}

We begin with the intercept model then add predictors one at a time until all predictors are in the model. The choice of predictor to be added to the model at each step depends on which among the remaining predictors gives the maximum additional improvement to the fit (Deviance). The single best model is chosen using the Akaike Information Criterion (AIC) and Bayesian Information Criterion (BIC). AIC and BIC are computed as follows:

$$
\begin{aligned}
& A I C=-2 l+2 p, \\
& B I C=-2 l+p \log (n),
\end{aligned}
$$

where $p$ is the number of predictors, $n$ is the number of observations, and $l$ is the log-likelihood.

\subsection{Prediction metrics}

A confusion matrix contains information about actual and predicted classifications done by a

\begin{tabular}{|c|c|c|c|c|c|}
\hline & \multicolumn{3}{|c|}{ Predicted Class } & Total & Rate \\
\hline \multirow{3}{*}{ Actual Class } & & $=1$ & $\widehat{Y}=0$ & & \\
\hline & $Y=1$ & $T P$ & $F N$ & $T P+F N$ & $T P R=\frac{T P}{T P+F N}$ \\
\hline & $Y=0$ & $F P$ & $T N$ & $F P+T N$ & $F P R=\frac{F P}{\Gamma D F M}$ \\
\hline
\end{tabular}
classification system. Table 1 shows the confusion matrix for a two-class classifier. The true positive rate $(T P R)$ is given by the ratio of the true positive $(T P)$ to the sum of the true positive and false negative $(F N)$. The false positive rate $(F P R)$ is obtained as the ratio of the false positive $(F P)$ to the sum of the false positive and true negative $(T N)$.

Table 1. Confusion Matrix

At different thresholds says $0.00,0.01, \ldots, 1.00$, a graph of $T P R$ (sensitivity) against $F P R$ (1- specificity) is plotted to obtain the receiver operating characteristic (ROC) curve. Numerically, the area under the ROC curve also referred to as the area under curve (AUC). The AUC measures the prediction accuracy of the logit model. 


\subsection{C-Index}

Based on our data, $(i, j)$ are the actual response observations labelled 1 and 0 while $\pi\left(\beta \mid X_{i}\right)$ and $\pi\left(\beta \mid X_{j}\right)$ are the corresponding predicted probabilities. For each pair $(i, j)$, the C-Index is defined as:

$$
C_{i, j}=\operatorname{Pr}\left[\pi\left(\beta \mid X_{i}\right)>\pi\left(\beta \mid X_{j}\right) \mid Y_{i}=1, Y_{j}=0\right] .
$$

Equivalently,

Let,

$$
C_{i, j}=\operatorname{Pr}\left[X_{i}^{\prime} \beta>X_{j}^{\prime} \beta \mid Y_{i}=1, Y_{j}=0\right] .
$$

$\eta_{i}^{(1)}=X_{i}^{\prime} \beta \mid Y_{i}=1$,

$\eta_{j}^{(0)}=X_{j}^{\prime} \beta \mid Y_{j}=0$,

$N_{1}=$ Number of $1^{\prime}$ s, and

$N_{0}=$ Number of 0 's.

For all pairs $(i, j)$, the $\mathrm{C}$-Index is estimated by the test statistic:

$$
C=\frac{1}{N_{1} \times N_{0}} \sum_{i=1}^{N_{1}} \sum_{j=1}^{N_{0}} I\left\{\eta_{i}^{(1)}, \eta_{j}^{(0)}\right\},
$$

where

$$
I\left\{\eta_{i}^{(1)}, \eta_{j}^{(0)}\right\}=\left\{\begin{array}{c}
1, \text { if } \eta_{i}^{(1)}>\eta_{j}^{(0)} \\
0.5, \text { if } \eta_{i}^{(1)}=\eta_{j}^{(0)} \\
0, \text { if } \eta_{i}^{(1)}<\eta_{j}^{(0)}
\end{array}\right.
$$

$C<0.5$ Implies poor prediction accuracy by the model. If $C=0.5$, then the model prediction accuracy is the same as a random guess. When $C>0.5$ and $C=1$ are indications of better and perfect model prediction accuracies respectively.

\section{RESULTS AND ANALYSIS}

\subsection{Model assessment metrics}

This study used the GYTS data to specify a model for predicting the likelihood of smoking at the junior high school level in Ghana. Table 2 presents results on the model assessment metrics using both the training and the testing sets. A full logit model with 32 predictors and two selected logit models based on forward selection with the least AIC/BIC were estimated and compared using C-index and C-Index per Predictor. The model with the least AIC of 2029.06 chose 14 predictors while the model with the least BIC of 2086 resulted in 6 predictors shown in Appendix.

The C-Index and the C-Index per Predictor were used to check the predictive accuracies of the full model and the two selected models. The C-Index for the full model $(85.15 \%)$ was larger than that of the AIC-based, and BIC-based models in the training set. The C-Indexes for the AIC-based and BIC-based models on the training set were $84.65 \%$ and $82.00 \%$ respectively. Similarly, the C-Index for the full model $(80.67 \%)$ was larger than that of the AIC-based and BIC-based models in the testing set. The C-Indexes for the AIC-based and BIC-based models on the testing set were $81.74 \%$ and $80.86 \%$ respectively shown in Table 1. The C-Index per Predictor for the full model, AIC-based, and BIC-based models on the training set were $2.67 \%, 6.05 \%$ and $13.67 \%$ respectively. Similarly, the C-Indexes per Predictor for the three models on the testing set were $2.52 \%, 5.84 \%$, and $13.48 \%$ respectively shown in Table 2 .

Table 2. Model Assessment Metrics

\begin{tabular}{lccc}
\hline \multicolumn{1}{c}{ Description } & Full Model & AIC-Model & BIC-Model \\
\hline \# of Predictors Selected & 32 & 14 & 6 \\
C-Index - Training Set (\%) & 85.51 & 84.65 & 82.00 \\
C-Index - Testing Set (\%) & 80.67 & 81.74 & 80.86 \\
C-Index Per Predictor - Training Set (\%) & 2.67 & 6.05 & 13.67 \\
C-Index Per Predictor - Testing Set (\%) & 2.52 & 5.84 & 13.48 \\
\hline
\end{tabular}

IJPHS Vol. 7, No. 4, December 2018: 223 - 230 
A comparison of the three C-Indexes per predictor indicated that the BIC-based model had the highest power per predictor, followed by the AIC-based model both in the training and testing sets. Often, model assessment metrics based on training sets tend to lead to overfitting. Therefore, testing sets are used to choose the most appropriate model. The chosen model would be based on the testing set with C-Index per Predictor and parsimony. The BIC-based model fit these criteria.

\subsection{ROC curves of the Full, AIC, and the BIC-based models}

Figure 1 shows the ROC curves of the Full (left), AIC (middle) and the BIC (right)-based models. Figure 1 compares the AUC for the training (grey) and the testing (black) sets of the three models. Essentially, the AUC is numerically the same as the C-Index.

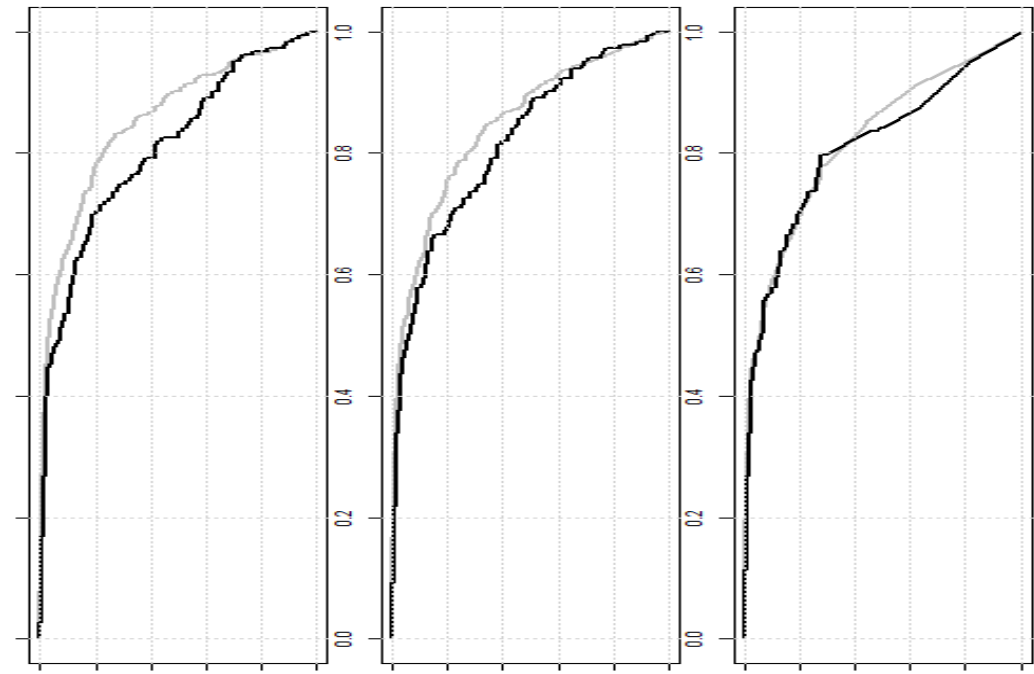

Figure 1. ROC Curves for Full (left), AIC (middle), and BIC (right)-Based Models

\subsection{Predictors of smoking tendencies}

Table 3 presents the fitted BIC-Model with six (6) predictors that resulted in the highest C-Index per predictor. The six predictor variables significantly predicted students' smoking tendencies. First, where students smoked significantly predicted their smoking tendencies. Participants who "Never smoked cigarettes" served as the comparison or reference group. Participants who smoked at home, school, at a friend's house, at public events or other places, had significantly higher odds of smoking than those who indicated they did not smoke. Second, having their closest friend smoke was a significant predictor of participants' smoking tendencies. Students who indicated none of their closest friends smoked served as the comparison group. Participants who indicated some, most or all of their friends smoked had significantly higher odds of smoking than those who had zero friends who smoked. Third, the "number of days" people have smoked in students' homes in thestudents' presence significantly predicted their tendency to smoke. Students who indicated they had zero people smoke in their house in the past 7 days served as the comparison group. Those who indicated 1-2, 3-4, 5-6 or 7 people smoked in their house the past 7 days had significantly higher odds of smoking. Fourth, having chewed any form of tobacco products other than cigarettes in the past 30 days significantly predicted students' smoking tendencies. Students who indicated they ever chewed any form of tobacco products other than cigarettes in the past month had higher odds of smoking cigarettes than those who did not. Fifth, a student's sex was a significant predictor of the tendency to smoke. Females had a lower odd of smoking cigarettes than their male counterparts. Finally, whether or not discussing the effects of smoking in JHS classes about the effects of smoking as a predictor of smoking tendencies resulted in mixed results. Students who responded "Yes" to discussing about the effects of smoking in their classes served as the comparison group. Students who responded "No" had significantly lower odds of smoking cigarettes. There were no significant differences in the tendencies to smoke cigarettes for those who responded "yes" and those who indicated they were not sure. 
Table 3. Fitted Bayesian Information Criterion-Model

\begin{tabular}{|c|c|c|c|}
\hline Variable & z-Score & Odds Ratio & Probability \\
\hline (Intercept) & -11.892 & 0.116 & 0.104 \\
\hline \multicolumn{4}{|l|}{ Where do you usually smoke? (Never smoked) } \\
\hline Home & 12.273 & 9.915 & 0.908 \\
\hline School & 3.637 & 2.955 & 0.747 \\
\hline Work & 5.091 & 19.631 & 0.952 \\
\hline Friends' House & 8.744 & 26.655 & 0.964 \\
\hline Social Events & 4.097 & 94.341 & 0.990 \\
\hline Public Places & 7.471 & 13.009 & 0.929 \\
\hline Other & 5.022 & 27.173 & 0.965 \\
\hline \multicolumn{4}{|c|}{ Do any of your closest friends smoke cigarettes? (None) } \\
\hline Some & 5.611 & 2.257 & 0.693 \\
\hline Most & 2.008 & 1.857 & 0.650 \\
\hline All & 3.627 & 3.547 & 0.780 \\
\hline \multicolumn{4}{|c|}{$\begin{array}{l}\text { During the past } 7 \text { days, on how days have many people have smoked in your home, } \\
\text { in your presence? (0) }\end{array}$} \\
\hline $1-2$ & 5.882 & 2.681 & 0.728 \\
\hline $3-4$ & 2.706 & 2.354 & 0.702 \\
\hline $5-6$ & 3.221 & 2.663 & 0.727 \\
\hline $5-7$ & 3.324 & 2.225 & 0.690 \\
\hline \multicolumn{4}{|c|}{$\begin{array}{l}\text { During the past } 30 \text { days (month) have you ever chewed any form of tobacco } \\
\text { products other than cigarettes? (Yes) }\end{array}$} \\
\hline No & -4.202 & 0.512 & 0.338 \\
\hline \multicolumn{4}{|l|}{ Sex (Male) } \\
\hline Female & -3.476 & 0.650 & 0.394 \\
\hline \multicolumn{4}{|c|}{$\begin{array}{l}\text { During this school year, did you discuss in any of your classes about the effects of } \\
\text { smoking? (Yes) }\end{array}$} \\
\hline No & -3.467 & 0.642 & 0.391 \\
\hline Not Sure & 1.312 & 1.309 & 0.567 \\
\hline
\end{tabular}

\section{DISCUSSION}

The present study used the GYTS 2009 data to specify a model for predicting the likelihood of smoking at the junior high school level in Ghana. A major finding of the study was that where students smoked significantly predicted their smoking tendencies-the home, school, a friend's house, and public events are environments that would increase the likelihood that JHS students would smoke. For example, parental smoking behaviors are important in reducing smoking intentions among Ghanaian youth [13]. Adolescents with parents who smoke at home would more likely have access to tobacco at home [18]. It is also a common practice for parents and other adults in Ghana to send their children or other minors to purchase tobacco products for them (parents/other adults). A related finding was that the number of people who smoked in students' homes in their presence significantly predicted students' likelihood to smoke. Tobacco control measures in Ghana are specified in the Public Health Act 2012 (Act 851) [19]-the Act prohibits smoking in public places among other restrictions. Unfortunately, lack of enforcement of the Act undermines Government and community efforts to control the negative effects of tobacco use [20].

A second finding was that students who smoked were more likely to have closest friends who also smoked. This finding is consistent with previous findings that smokers were likely to have friends who smoked [15]. Peer influence, according to [21], was a risk factor for smoking. Students who had been offered a cigarette were more likely to smoke. In addition, those with one or more friends had higher odds to smoke than those who had no friends [21]. Thus, strategies for increasing adolescents' self-esteem and decisionmaking capabilities are critical for smoking prevention in Ghana. As noted by [22], adolescents with high levels of self-esteem would be less susceptible to peer pressure than their counterparts with low levels of selfesteem.

Third, the use of any form of tobacco products other than cigarettes predicted students' smoking tendencies. Research has shown that individuals who chewed other forms of tobacco products in the past month had higher odds of smoking cigarettes than those who did not. Smokeless tobacco is a significant predictor of smoking initiation among young adult males. Participants who used smokeless tobacco were more likely to begin smoking that nonusers [23]. Furthermore, smokeless tobacco has been associated with health risks such as cancer causing substances [24] and adverse cardiovascular health [25], and it is not a feasible substitute for cigarette smoking [24].

Finally, male students had higher prevalence of smoking than their female counterparts. This finding is consistent with that of [20], who reported higher smoking tendencies among Ghanaian adult males than in 
females. Thus, early smoking intervention programs among school-aged adolescents is warranted as bad habits are difficult to break. This would promote healthy lifestyles choices among students such as the avoidance of alcohol and tobacco consumption [26].

Findings from the present study have implications for school and community health. First, school smoking prevention programs need to include parents and community leaders. Second, students' self-esteem and decision making capabilities must be addressed in school intervention programs aimed at smoking prevention. Students with high self-esteem would more likely resist smoking uptake due to peer pressure [22]. In addition, students need the skills to help them make good decisions that would lead to healthy lifestyles. Finally, the data used for the present study were the most current on tobacco survey data for Ghana, and were published in 2009. Therefore, it is incumbent on Ghana's stakeholders in the health sector to implement the GYTS to gain insight on the most current smoking behaviors among school-going aged adolescents in the country.

The current study utilized a closed-ended survey (GYTS) to examine junior high school students' smoking tendencies. Future research could use other approaches to gain futher insight on smoking among adolescents. First, future researchers should include qualitative approaches such as focus groups to allow participants to freely express their feelings. This would provide better understanding of students' tendencies toward smoking. Second, the present study provided aggregated national data. Future research using data disaggregated by region would reveal regional disparities, if any, relating to JHS students' smoking tendencies. This would allow policy makers and health and school administrators to target region specific predictors of tendiencies for effective smoking prevention interventions. Finally, future researchers should include multi-age populations including junior high, senior high schools and colleges and universities. Results of such studies would provide a comprehensive information on the prevalence of smoking for the respective educational levels in the country.

\section{CONCLUSIONS}

The present study showed that environmental issues were important factors that impacted junior high school students' smoking tendencies. The home, school, a friend's house, and public events were environments that significantly predicted smoking behaviors. In addition, social interactions, especially, with peers are significant determinants of students' smoking behaviors. Furthermore, the study revealed that the Logit model was a powerful statistical tool for identifying predictors of Ghanaian junior high school students' smoking behaviors.

\section{REFERENCES}

[1] World Health Organization, "Global Youth Tobacco Survey," 2015. Retreived May 20, 2018 from http://www.who.int/tobacco/surveillance/gyts/en/.

[2] Ghana News Agency, "CSOs urge NDPC to integrate tobacco measures in development plan." September 2016. Retrieved July 20 from https://www.ghanabusinessnews.com/2016/09/28/csos-urge-ndpc-to-integrate-tobaccomeasures-in-development-plan/.

[3] Mathers, C. D, and Lonca, D., "Projections of Global Mortality and Burden of Disease from 2002 to 2030," PloS Medicine, vol/issue, 3(11), pp. e442, 2006.

[4] Eriksen, M., Mackay, J., and Ross, H., "The Tobacco Atlas, Fourth Edition.” Atlanta Georgia: American Cancer Society, Inc.; 2012. Retrieved May 10, 2018 from http://tobaccoatlas.org/uploads/Images/PDFs/Tobacco_Atlas_

[5] Beyer, J. D., and Brigden, L.W, editors. "Tobacco Control Policy Strategies Successes and Setbacks: The World Bank," 2003.

[6] Tomori, O., Omaswa, F., Bekure, S., Blecher, E., Devotsu, R., Haile-Mariam, et al., "Preventing a Tobacco Epidemic in Africa: A call for Effective Action to Support Health, Social, and Economic Development." Report of the Committee on the Negative Effects of Tobacco on Africa's Health, 2014. Economy and Development. 2014. Retrieved October 17, 2018 from http://hdl.handle.net/20.500.11910/2186.

[7] Drope, J, "Tobacco Control in Africa: People, Politics and Policies." Anthem Press, 2011.

[8] John, R. M., Mamudu, H.M, and Liber, A. C., "Socioeconomic Implications of Tobacco Use in Ghana," Nicotine Tobacco Research, vol., 14, pp. 1205-12, 2012.

[9] Addo, J., Smeeth, L., Leon, D.A., "Smoking Patterns in Ghanaian Civil Servants: Changes Over Three Decades," International Journal of Environmental Research and Public Health, vol., 6, pp. 200-208, 2009.

[10] Thun, M., Peto, R., Boreham, J., and Alan D Lopez, A. D., "Stages of the Cigarette Epidemic on Entering its Second Century." Tobacco Control, vol., 21, pp. 96e101. 2012. DOI: 10.1136/tobaccocontrol-2011-050294.

[11] World Health Organisation, "Global youth tobacco survey," 2011. Fact sheet," Retrieved April 6, 2018 from http://www.cdc.gov/tobacco/global/gyts/ factsheets/afr/2006/Ghana_factsheet.htm.

[12] Asma, S., Mackay, J., Song, S. Y., Zhao, L., Morton J, Palipudi, K.M., et al., "The GATS Atlas," 2015. CDCFoundation, Atlanta, GA. Retrieved July 13, 2018 from http://www.gatsatlas.org/.

[13] Doku, D., Raisamo, S., and Wiium, N., "The Role of Tobacco Promoting and Restraining factors in Smoking Intentions among Ghanaian Youth,” BMC Public Health, vol. 12, pp. 662, 2012. 
[14] Ghana News Agency, “CSOs urge NDPC to Integrate Tobacco Measures in Development Plan,” September 2016. Retrieved August 5 from https://www.ghanabusinessnews.com/2016/09/28/csos-urge-ndpc-to-integrate-tobaccomeasures-in-development-plan/.

[15] Owusu-Dabo, E., Lewis, S., McNeill, A., Anderson, S., Gilmore, A., and Britton, J., "Smoking in Ghana: A Review of Tobacco Industry Activity,” Tobacco Control, vol. 18, pp. 206-211, 2009.

[16] World Health Organization, "Global Tobacco Surveillance System Data (GSTTData)," 2015. Retrieved August 5 from https://nccd.cdc.gov/GTSSDataSurveyResources/Ancillary/DataReports.aspx?CAID=2

[17] Charpentier, A., Editor, "Computational Acturial Science with R," Boca Raton, FL: Taylor \& Francis Group," 2015.

[18] Rainio, U.S., and Rimpelä, A.H., "Home-based sourcing of tobacco among adolescents," Preventive Medicine, vol. 48, pp. 378-382, 2009.

[19] Govement of Ghana, "Public Health Act 2012 (Act 851)," 2012. Govenement Printer, Assembly Press, Accra.

[20] Nketiah-Amponsah, E., Afful-Mensah, G., and Ampaw, S., Determinants of cigarette smoking and smoking intensity among adult males in Ghana. BMC Public Health, vol. 18, pp. 941, 2018. DOI: http://doi.org/10.1186/s12889-018-5872-0.

[21] Oyewole B. K., Animasahun, V. J., and Chapman, H. J., "Tobacco Use in Nigerian Youth: A Systematic Review. PLoS ONE, vol. issue 13(5), pp. e0196362. 2018. DOI: https://doi.org/10.1371/journal.pone.0196362.

[22] Croghan, I. T., Bronars, C., Patten, C. A., Schroeder, D. R., Nirelli, L. M., Thomas, J. L. et al., "Smoking Related to Body Image Satisfaction, Stress, and Self-esteem in Young Adults?" American Journal of Health Behavior. vol.issue, 30(3), pp. 322-333, 2006.

[23] Haddock, K. C., Weg, M. V., DeBon, M., Kleige, R. C., Talcott, W. C., Lando, H. et al., "Evidence that Smokeless Tobacco Use is a Gateway for Smoking Initiation in Young Adult Males," Preventive Medicine, vol./issue, 32(3), pp. 262-267, 2001. DOI: https://doi.org/10.1006/pmed.2000.0802.

[24] Zhou, J., Michaud, D. S., Langevin, S. M., McClean, M. D., Eliot, M., and Kelsey, K. T., "Smokeless Tobacco and Risk of Head and Neck Cancer: Evidence from a Case-Control Study in New England," International Journal of Cancer, vol. 132, pp. 1911-1917, 2013. Retrieved August 15, 2018 from https://onlinelibrary.wiley.com/doi/pdf/10.1002/ijc.27839.

[25] Gupta, R., Gurm, H., and Bartholomew, J. R., "Smokeless Tobacco and Cardiovascular Risk," Archives of Internal Medicine, vol./issue, 164(17), pp. 1845-1849, 2004. DOI:10.1001/archinte.164.17.1845.

[26] Ghana Education Service, "School Health Education Programme: Policy Guidelines," Ghana Education Service, Accra, 2012 